\title{
Proposal for improving of paddy rice drying process in dryers inclined pools
}

\author{
Propuesta de mejoramiento del proceso de secado de arroz paddy en secaderos tipo \\ albercas inclinadas
}

\author{
L. E. Vera-Duarte (iD; F. Moreno-Gamboa iD; J. R. Eugenio-López iD \\ DOI: https://doi.org/10.22517/23447214.24554 \\ Artículo de investigación científica y tecnológica
}

\begin{abstract}
The operation of inclined type dryers for paddy rice is studied to improve their operation and efficiency, considering the variables of drying time, humidity distribution in the rice layer after drying and air velocities within the plenum. Simulating the distribution and velocities of the air flow before crossing the rice layer, the outlet ducts to the plenum are relocated and dampers are placed to distribute the flow evenly. On the other hand, it is proposed to replace the flat-type mesh with a zigzag-type mesh. To verify the proposed modifications, a scale model was built to determine the humidity and drying time variation inside the rice layer, obtaining more uniform moisture percentages within the rice layer and a decrease in drying time.
\end{abstract}

Index Terms - dryers inclined pools, improving paddy rice dryers paddy rice drying,

Resumen - Se estudia el funcionamiento de los secaderos tipo inclinado para arroz paddy, con el fin de mejorar su operación y eficiencia, considerando las variables de tiempo de secado, distribución de la humedad en la capa de arroz después del secado y velocidades del aire dentro del plenum. Simulando la distribución y velocidades del flujo de aire antes de cruzar la capa de arroz se reubican los conductos de salida al plenum y se colocan dampers que distribuyan uniformemente el flujo. Por otro lado, se propone la sustitución de la malla tipo plana por una malla tipo zigzag. Para verificar las modificaciones propuestas se construyó un modelo a escala para medir la variación del tiempo de secado y la humedad dentro de la capa de arroz paddy, obteniendo porcentajes de humedad más uniformes dentro de la capa de arroz y disminución del tiempo de secado.

Palabras claves - mejoramiento de secado de arroz, secado de arroz, secaderos inclinados,

This manuscript was sent on October 21, 2020 and accepted on June 05, 2021. The authors would like to express their gratitude to the Universidad Francisco de Paula Santander for the support provided for the development of this project.

L. E. Vera-Duarte is with Francisco de Paula Santander University as professor, Cúcuta, Colombia (e-mail: luisemiliovd@ufps.edu.co).

\section{INTRODUCTION}

$\mathrm{R}$ ICE drying is a problem in rice producing countries. It sometimes becomes a crucial problem in humid tropical climates, it is a critical post-harvest operation that defines the quality of rice. Delayed drying, incomplete drying or inefficient drying will reduce grain quality and increase post-harvest losses. The inclined bed dryer (IBD) is quite common for complete drying of rice in a single stage with deep fixed bed which gives advantages for an easy and fast discharge of rice. This is normally used for drying high moisture rice such as that produced in Colombia between 24 to $28 \%$ (wb) [1], this is built for a layer of rice between 0.8 and $1.0 \mathrm{~m}$. The moisture gradient in the final product is between 12 to 14 percent (wb) [2], Some reviews have been found on the study [3] [4] of the energy efficiency of inclined type dryers in which they focus on studies of thermal and electrical energy consumption, but not on the improvement of the air flow distribution at the entrance of the paddy rice layer and the uniform drying of the rice, so that the search for information and references specifically for this topic is unsuccessful due to the scarcity of information.

The artificial drying of grains at high temperatures is a process faster and more controllable than the natural drying, by not dependent on climatic conditions and prevents damage that can occur during natural drying.

This paper presents a proposal for improvement of the rice dryers inclined pools to reduce drying time, costs and the percentage humidity with which rice leaves.

\section{A. Paddy rice}

It is that recently harvested, with humidity between 24 and 28 percent and impurities between 3 to 6 percent.

F. Moreno-Gamboa. is with Francisco de Paula Santander University as professor, Cúcuta, Colombia (e-mail: faustinomg@ufps.edu.co).

J. R. Eugenio-López. is with Francisco de Paula Santander University as professor, Cúcuta, Colombia (e-mail: joserafaelel@ufps.edu.co). 


\section{B. Inclined pool or drying silo}

Deposits where the rice to dry is place are construct with slopes between 32 to $35^{\circ}$, with a depth between 0.8 to $1.0 \mathrm{~m}$. Those with less slope need help for their total discharge, those of greater slope, $34^{\circ}$ and $35^{\circ}$, tend to precipitate and suffer spontaneous rolling. The slope that balances problems and advantages is between 33 and $34^{\circ}$ (Fig. 1).

\section{Drying of rice}

Operation by which is eliminated a certain amount of humidity. The drying time depends on the percentage of humidity with which the rice is received, which should have a humidity between 12 and 13 percent at the end [2], in a process that can last between 48 and 60 hours [5].

\section{MATERIALS AND METHODS}

Paddy rice is dried in drying silos (Fig. 1), deposited on a flat mesh (Fig. 2 and Fig. 3), hot air is supplied at the bottom, which passes through the rice layer, and maintains the silos at a temperature between 40 and $45^{\circ} \mathrm{C}$ [4]. For continuous drying, centrifugal fans are used to push it. the air is heated by the heat obtained from coke combustion, coke is used due to its availability northeastern Colombia, cost, it burns with no smoke, being environmentally cleaner than coal.

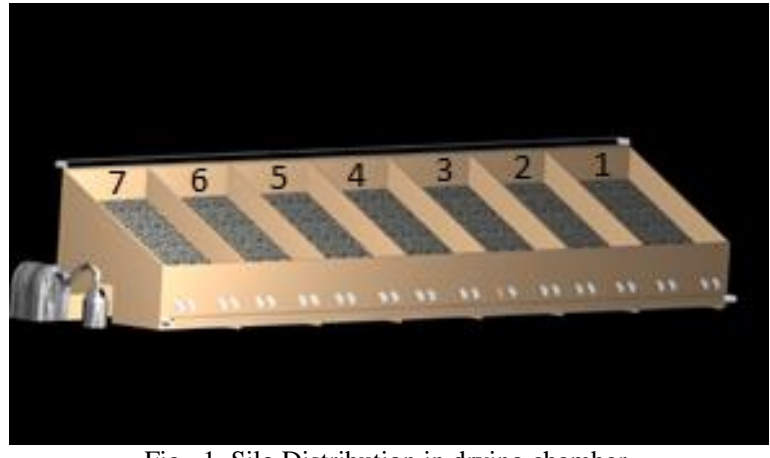

Fig. 1. Silo Distribution in drying chamber.

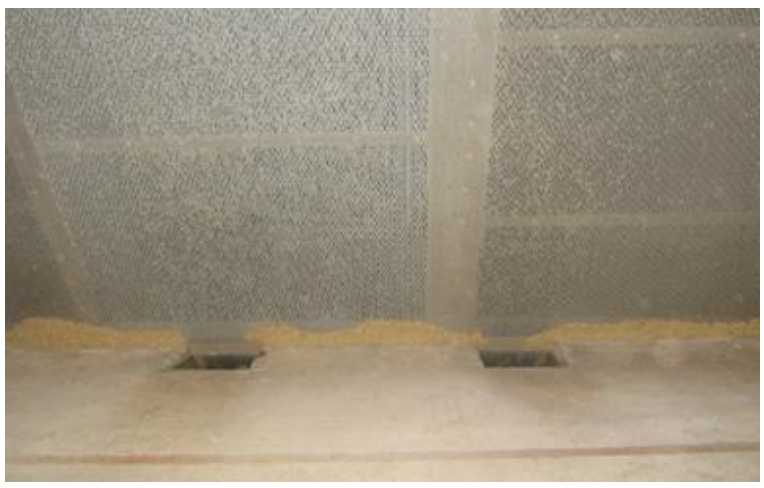

Fig. 2. $2 \mathrm{~m} \times 1 \mathrm{~m}$ perforated galvanized sheet gage 18 , with holes of $1.6 \mathrm{~mm} \times$ $2 \mathrm{~mm}$, that supports the layer rice between $0.8 \mathrm{~m}$ to $1 \mathrm{~m}$ of deep, and the hot air pass through it.

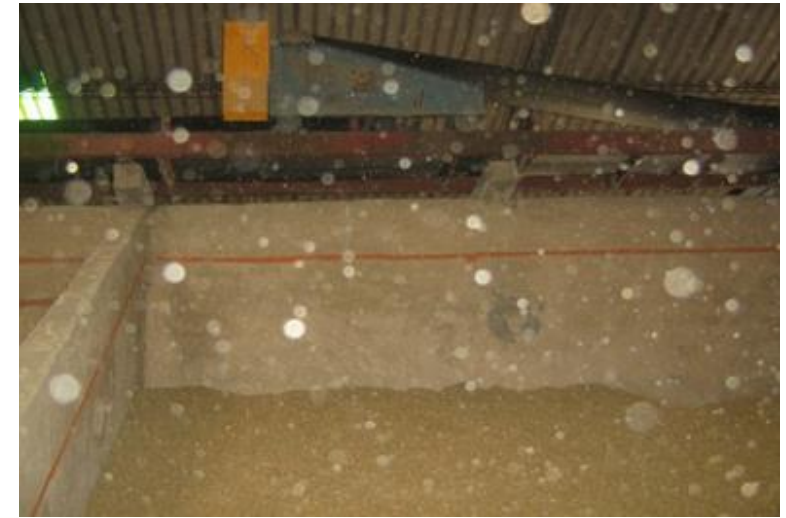

Fig. 3. Placement of layer of rice to dry.

For the initial analysis of the operation of the dryer, an imaginary volumetric distribution was made (Fig. 4), zones where was taken on air velocities (see Table I).

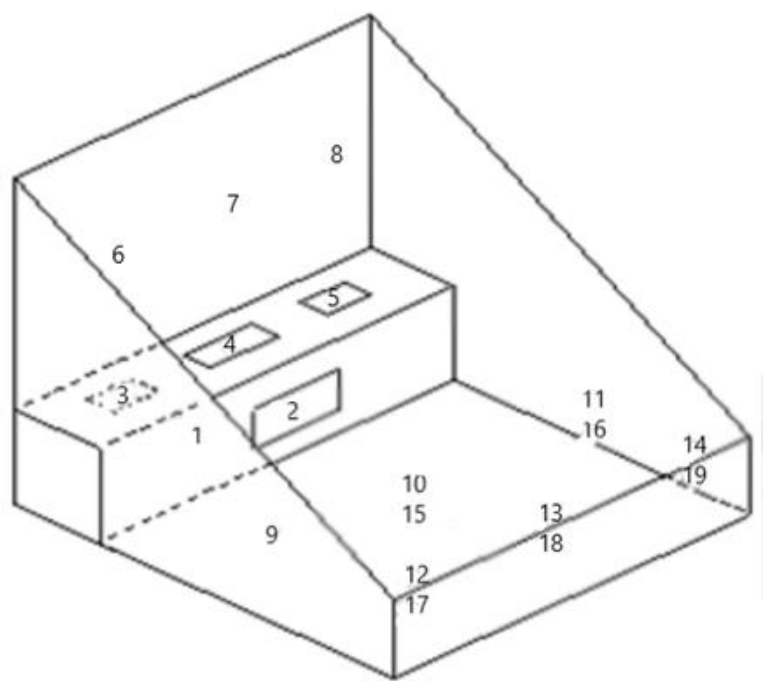

Fig. 4. Positions within the silo to determine air speed

TABLE I.

Flow Velocities IN M/S Of AIR INTO The Silo.

\begin{tabular}{|c|c|c|c|c|c|c|c|}
\hline \multirow{2}{*}{ Position } & \multicolumn{7}{|c|}{ Silos } \\
\hline & 1 & 2 & 3 & 4 & 5 & 6 & 7 \\
\hline 1 & 3.1 & 6.0 & 7.0 & 10.6 & 12.1 & 14.4 & 20.1 \\
\hline 2 & 3.4 & 6,2 & 6.8 & 10.1 & 10.9 & 12.3 & 15.8 \\
\hline 3 & 3.8 & 5.3 & 5.4 & 6.5 & 5.6 & 3.6 & 0.4 \\
\hline 4 & 3.4 & 5.6 & 7.3 & 9.2 & 9.6 & 8.2 & 0.6 \\
\hline 5 & 2.9 & 5.1 & 6.4 & 9.6 & 10.0 & 10.7 & 6.5 \\
\hline 6 & 0.0 & 0.7 & 0.0 & 0.8 & 0.6 & 1.3 & 1.0 \\
\hline 7 & 1.8 & 0.9 & 1.2 & 1.2 & 0.0 & 0.0 & 0.0 \\
\hline 8 & 1.2 & 2.7 & 3.3 & 4.0 & 3.6 & 3.2 & 2.6 \\
\hline 9 & 1.1 & 0.9 & 0.9 & 1.2 & 1.0 & 1.0 & 1.0 \\
\hline 10 & 0.0 & 0.0 & 0.0 & 0.0 & 0.0 & 0.0 & 0.0 \\
\hline 11 & 0.7 & 1.1 & 1.1 & 2.0 & 1.9 & 1.7 & 3.1 \\
\hline 12 & 1.0 & 0.9 & 0.8 & 1.0 & 1.1 & 1.0 & 0.8 \\
\hline 13 & 0.9 & 1.3 & 1.1 & 1.7 & 1.3 & 1.4 & 1.8 \\
\hline 14 & 0.0 . & 0.0 & 0.0 & 0.5 & 0.7 & 1.0 & 0.9 \\
\hline 15 & 0.0 & 0.0 & 0.0 & 0.0 & 0.0 & 0.0 & 0.0 \\
\hline 16 & 0.0 & 0.0 & 1.0 & 0.7 & 1.5 & 1.8 & 3.0 \\
\hline 17 & 0.5 & 0.8 & 0.7 & 1.0 & 0.9 & 0.9 & 1.3 \\
\hline 18 & 1.2 & 1.2 & 1.1 & 1.4 & 1.1 & 1.5 & 1.6 \\
\hline
\end{tabular}




$\begin{array}{llllllll}19 & 0.5 & 0.0 & 0.5 & 0.7 & 1.0 & 1.2 & 1.5\end{array}$

An imaginary distribution was made of the pool where the rice is deposited (Fig. 5), and data were taken on the moisture of the rice at different depths (see Tables II, III and IV). The measurement of the variation of moisture in the rice layer was made by densities difference. The initial moisture (with which arrives the freshly harvested rice) is measured with a moisture digital detector.

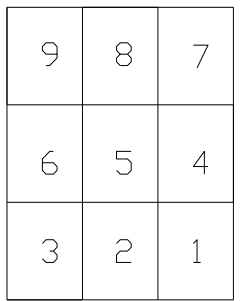

Fig. 5. Distribution of the pool sloped to humidity measurement.

TABLE II

Moisture Percentage On The Surface Of The Rice Layer.

\begin{tabular}{ccccccc}
\hline \hline & I & II & III & IV & V & VI \\
1 & 20.1 & 18.6 & 15.6 & 15.2 & 12.5 & 11.1 \\
2 & 22.7 & 22.3 & 23.1 & 22.7 & 13.2 & 11.2 \\
3 & 21.7 & 19.8 & 20.4 & 19.4 & 14.0 & 11.3 \\
4 & 22.6 & 22.7 & 22.3 & 21.5 & 14.6 & 12.3 \\
5 & 22.2 & 27.1 & 26.9 & 26.4 & 17.6 & 12.4 \\
6 & 22.7 & 22.4 & 22.0 & 22.1 & 13.6 & 11.3 \\
7 & 22.4 & 22.5 & 23.2 & 22.6 & 21.7 & 11.4 \\
8 & 26.0 & 25.3 & 23.5 & 24.9 & 16.9 & 11.2 \\
9 & 22.4 & 22.7 & 22.9 & 22.5 & 16.9 & 11.5 \\
average & $\mathbf{2 2 . 5 3}$ & $\mathbf{2 2 . 6 0}$ & $\mathbf{2 2 . 2 1}$ & $\mathbf{2 1 . 9 2}$ & $\mathbf{1 5 . 6 7}$ & $\mathbf{1 1 . 5 2}$ \\
\hline \hline
\end{tabular}

I, II, III, IV, V and VI are any times in moisture percentage was take.

TABLE III.

MOISTURE PERCENTAGE IN THE MIDDLE OF THE RICE LAYER

\begin{tabular}{ccccccc}
\hline \hline & I & II & III & IV & V & VI \\
1 & 14.3 & 14.3 & 13.7 & 13.0 & 11.6 & 9.8 \\
2 & 22.4 & 23.9 & 20.0 & 18.5 & 13.2 & 10.1 \\
3 & 16.5 & 15.6 & 15.3 & 14.5 & 12.0 & 10.6 \\
4 & 23.8 & 21.3 & 19.7 & 21.8 & 12.1 & 10.5 \\
5 & 25.8 & 17.7 & 15.0 & 15.4 & 11,7 & 10.7 \\
6 & 20.9 & 17.8 & 15.8 & 14.5 & 11.6 & 10.2 \\
7 & 25.4 & 23.0 & 19.7 & 20.5 & 13.4 & 10.4 \\
8 & 17.8 & 16.6 & 14.0 & 15.7 & 11.6 & 10.3 \\
9 & 23.7 & 19.5 & 19.2 & 17.1 & 11.7 & 10.9 \\
average & 21.18 & 18.86 & 16.93 & 16.78 & 12.10 & 10.39 \\
\hline \hline
\end{tabular}

I, II, III, IV, V and VI are any times in moisture percentage was take.

TABLE IV.

Moisture Percentage At The Bottom Of The Rice Layer

\begin{tabular}{ccccccc}
\hline \hline & I & II & III & IV & V & VI \\
1 & 12 & 11.4 & 12 & 10.8 & 10.4 & 10.2 \\
2 & 13 & 13.4 & 11.8 & 11.3 & 10.5 & 10.2 \\
3 & 12.9 & 11.6 & 11.4 & 11.4 & 11 & 10.1 \\
4 & 14.2 & 12.9 & 11.8 & 12.3 & 10.7 & 10.4 \\
5 & 13.6 & 12.3 & 11.8 & 11.3 & 10.8 & 10.3 \\
6 & 13.7 & 12.9 & 12 & 11.5 & 10.7 & 10.3 \\
\hline \hline
\end{tabular}

\begin{tabular}{ccccccc}
\hline \hline 7 & 14.8 & 15.4 & 12.1 & 11.8 & 10.7 & 10.3 \\
8 & 13.3 & 12.8 & 11.5 & 11.4 & 10.4 & 10.3 \\
9 & 13.7 & 12.5 & 12.2 & 11.3 & 10.2 & 10.6 \\
average & 13.47 & 12.80 & 11.84 & 11.46 & 10.60 & 10.30 \\
\hline \hline
\end{tabular}

I, II, III, IV, V and VI are any times in moisture percentage was take.

The drying time of the rice in some facilities in Colombia are between 48 and 60 hours (Table V), due to different factors such as differences moisture percentage, impurities, and the height of the layer of rice. In other facilities located in Colombia and Ecuador there are 24 hours [2] drying minimum times, therefore these greater times are generating higher costs in rice production.

TABLE V.

DRYING TIME.

\begin{tabular}{cccc}
\hline \hline & \multicolumn{2}{c}{ Humidity percentege } & Duration \\
\hline Silo & initial & end & hours \\
1 & 24.1 & 14.5 & 48.12 \\
2 & 23.5 & 10.3 & 48.12 \\
3 & 24.6 & 10.9 & 53.78 \\
4 & 24.7 & 12.2 & 59.3 \\
5 & 22.6 & 14.9 & 59.3 \\
6 & 25.5 & 10.2 & 53.78 \\
7 & 23.5 & 14 & 59.38 \\
\hline \hline
\end{tabular}

\section{PROPOSAL OF IMPROVEMENT.}

Hot air out of the vent flow tends to continue in the direction that leads directly hitting the silo wall forming inside the camera swirls (see Fig. 6) that generated sharp differences in the speed of the air flowing through the rice layer, causing differences in moisture into the rice layer.

The first proposed amendment seeks to improve the distribution airflow entering the rice layer, for this intends and to of adequacy of the holes in the air intake to the silo and placement of dampers that alter the distribution of airflow within the silo before crossing the rice layer. Based on simulation tests was achieved to establish dimensions optimal and placement of the dampers inside the dryer (Fig. 7 and Fig. 8). 


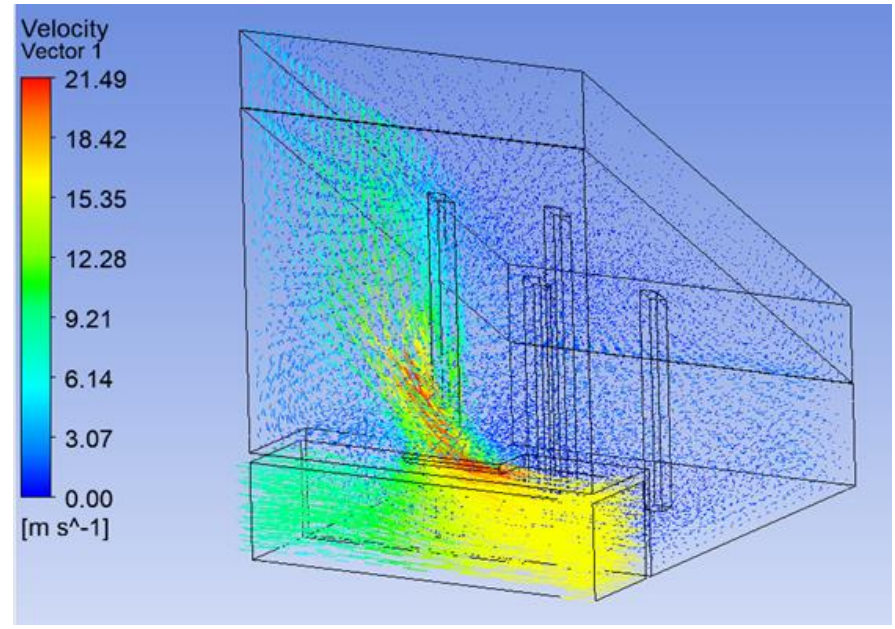

Fig. 6. Behavior of flow lines before first modification

For the simulation, the software Ansys 2019R2 cfx19 [6] was use, solving the continuity (1) and momentum (2) for an airflow as ideal gas to $325 \mathrm{~K}$.

The continuity equation written in a tensor form is:

$$
\frac{\partial \rho}{\partial t}+\nabla \cdot(\rho V)=0
$$

The momentum equation written in tensor form is:

$$
\frac{\partial \rho U i}{\partial t}+\nabla \cdot(\rho V i * V i)=\nabla \cdot\left(-p \delta+\mu\left(\nabla V i+(\nabla V i)^{T}\right)\right)+\rho g+
$$

In which:

- $\frac{\partial \rho U i}{\partial t}=$ speed of accumulation of amount of movement.

- $\nabla \cdot(\rho V i * V i)=$ speed of gain of amount of movement by convection.

- $\nabla \cdot(-p \delta)=$ pressure force acting on the element.

- $\quad \nabla \cdot\left(\mu\left(\nabla V i+(\nabla V i)^{T}\right)\right)=$ gain rate of amount of movement by viscous transport.

- $\rho g=$ force of gravity acting on the element.

- $S_{M P}=$ term source associated with the amount of movement, for the case to consider the rice layer as a porous medium.

$$
S_{M p}=-\frac{\partial P}{\partial x i}=-\frac{\mu}{K_{p e r m}} V i-K_{\text {perd }} \rho|V| V i
$$

Where:

- $K_{\text {perm }}=$ permeability of the rice layer

- $K_{\text {perd }}=$ loss coefficient associated with the passage of gases through the rice layer.
For the boundary conditions used in the simulation the average inlet and outlet velocities of the airflow through the main duct for a silo were taken, and for the outlet of airflow that go through the rice layer, the relative pressure as zero was taken. these are:

- air inlet speed to the duct $14.9 \mathrm{~ms}^{-1}$

- air outlet velocity through the pipeline $8.0 \mathrm{~ms}^{-1}$

- air outlet pressure after traversing the rice layer of $0.0 \mathrm{kPa}$

The turbulence model used was k-epsilon, applied for turbulent flow and negligible viscosity, for non-buoyant flow.

The rice layer was model as a porous medium with direction of flow only in the direction $\mathrm{y}$, with permeability of $0.001 \mathrm{~mm}^{2}$ [7] and coefficient of resistance of $0.5 \mathrm{~m}^{-1}$ [5].

The paddy rice wet is deposited on flat mesh. The second improvement proposed is the change of flat mesh to zigzag mesh tip, to have a greater contact area of the hot air with bottom side paddy rice and improve the distribution of the air when go across the rice layer.

\section{RESULTS}

With the objective to measure the variation in the different parameters involved of rice drying with the proposal improvements a scale 1:10 model [8] (Fig. 9) was construct.

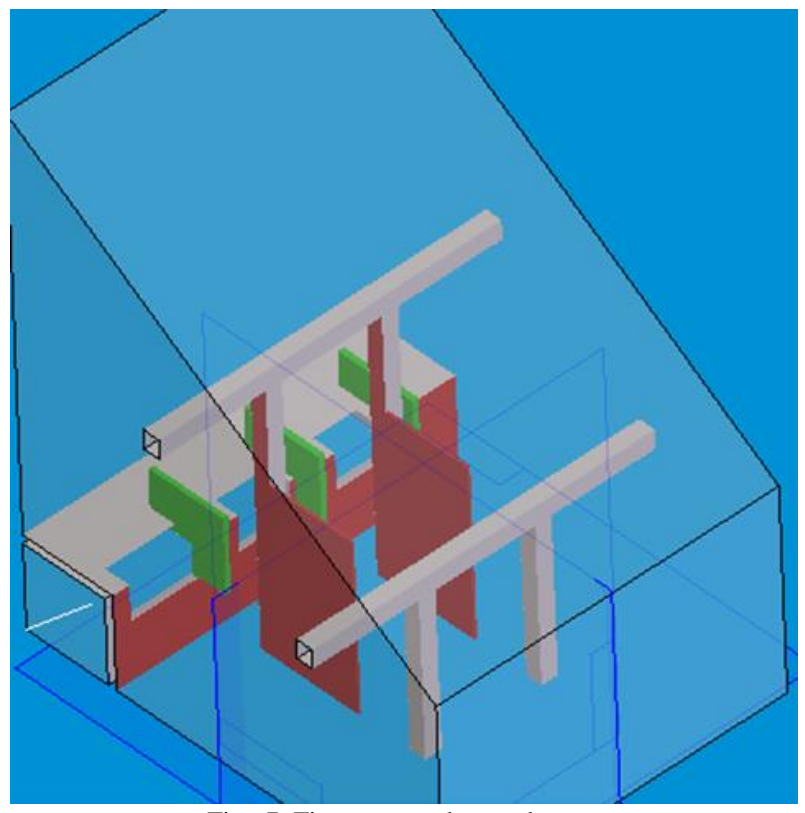

Fig. 7. First proposed amendments 


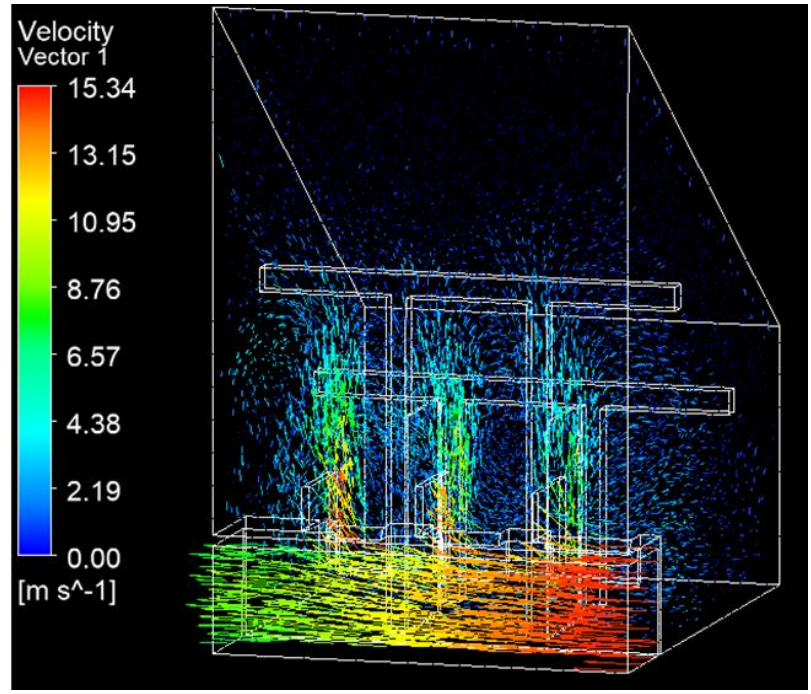

Fig. 8. Behavior of flow lines after first modification

In the prototype to determine the changes obtained for the proposed of adequacy of the holes in the air intake to the silo, placement of dampers and change of flat to zig zag mesh, the process started measuring rice initial humidity, then humidity controls were done in different moments according to the indicated positions in Fig. 5. The obtained results are shown in table VI, where it is observed that with the suggested modifications, the drying time is reduced from 48 minimum to 25 hours about.

As well in the prototype has carried out trials with both types of meshes to determine the changes obtained. The process started measuring humidity initial rice. Then humidity controls were done every sometime in the indicated positions in Fig. 5.

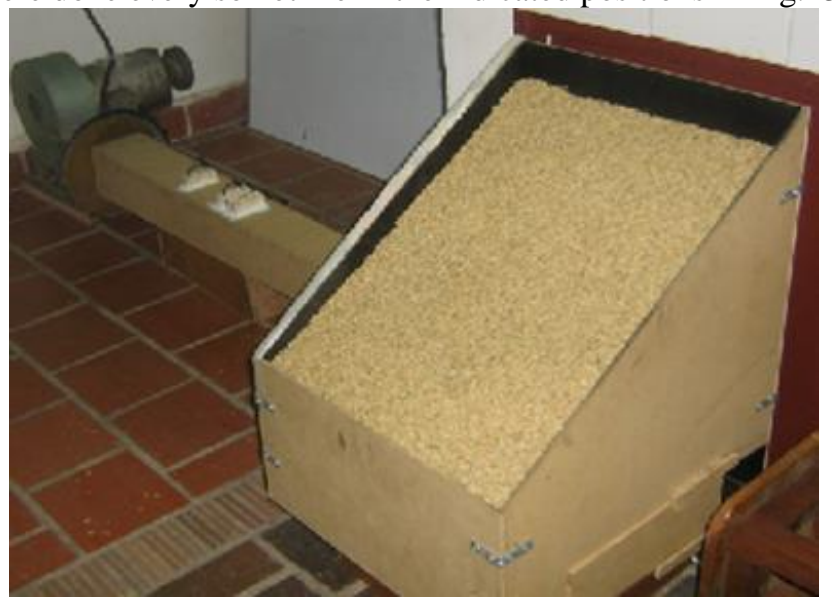

Fig. 9. Scale model.

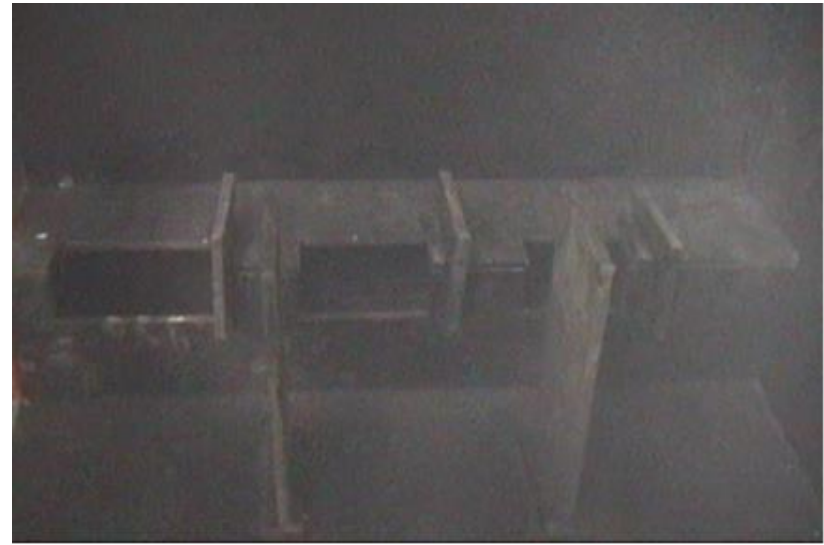

Fig. 10. Photograph of the scale with first proposed amendments

TABLE VI.

DRYING TIME WITH DAMPERS

\begin{tabular}{cccccccc}
\hline \hline $\begin{array}{c}\Delta \mathrm{t} \\
\text { (hours) } \\
\text { zone }\end{array}$ & 0 & $5: 15$ & $9: 05$ & $12: 10$ & $21: 30$ & $25: 35$ & $30: 05$ \\
1 & 21.6 & 23.0 & 20.6 & 17.4 & 16.4 & 11.6 & 11.0 \\
2 & 21.6 & 19.6 & 17.4 & 15.2 & 14.4 & 14.0 & 11.6 \\
3 & 21.6 & 20.0 & 17.6 & 16.0 & 14.1 & 12.9 & 10.8 \\
4 & 21.6 & 20.5 & 19.4 & 18.6 & 14.0 & 12.7 & 11.5 \\
5 & 21.6 & 20.6 & 18.2 & 16.8 & 15.2 & 12.2 & 11.0 \\
6 & 21.6 & 20.0 & 18.0 & 16.4 & 15.6 & 12.6 & 10.6 \\
7 & 21.6 & 19.4 & 15.3 & 15.8 & 12.4 & 12.2 & 10.2 \\
8 & 21.6 & 19.8 & 15.3 & 13.6 & 12.9 & 12.0 & 11.2 \\
9 & 21.6 & 19.5 & 15.3 & 13.6 & 13.2 & 12.4 & 11.0 \\
average & 21.6 & 20.3 & 17.5 & 15.9 & 14.2 & 12.5 & 11.0 \\
\hline \hline
\end{tabular}

The change of flat to type zigzag mesh cause that within rice layer moisture content is more homogeneous and as well reduce the time of drying according to Table VII.

\begin{tabular}{|c|c|c|}
\hline \multicolumn{3}{|c|}{$\begin{array}{l}\text { TABLE VII. } \\
\text { DRYING TIME }\end{array}$} \\
\hline mesh & flat & zig zag \\
\hline $\mathrm{kg}$ & 16 & 14 \\
\hline Average initial moisture percentage & 22.50 & 21.60 \\
\hline Average final moisture percentage & 15.93 & 12.5 \\
\hline $\begin{array}{c}\text { Percentage of average moisture } \\
\text { removed }\end{array}$ & 6.57 & 9.1 \\
\hline hours & 20 & 14.49 \\
\hline
\end{tabular}

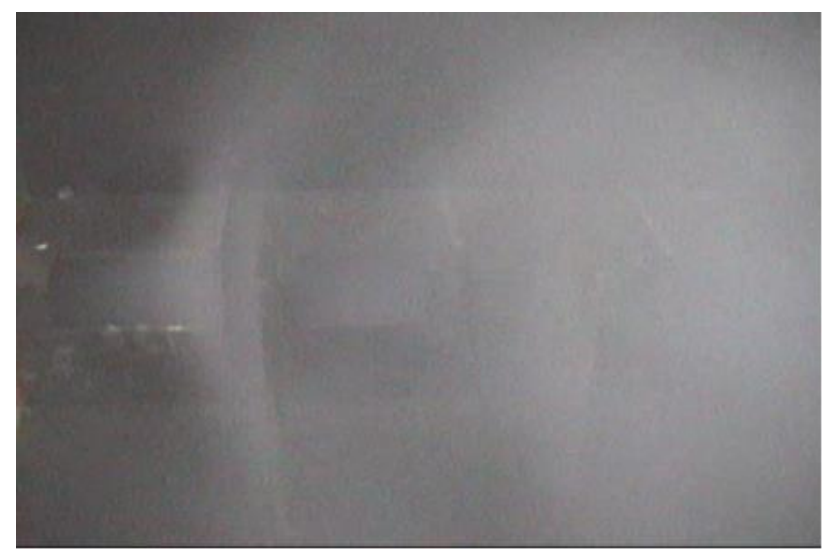

Fig. 11. Photograph of the scale with first proposed amendments and trial model. 
A thermo-economic evaluation of the process is suggested and to study the use of other environmental cleaner sources of energy to heat the airflow.

\section{REFERENCES}

[1] Castillo Álvaro and Gaviria Jaime., Molineria de arroz en los tropicos. Ediagro Ltda, 2000.

[2] P. Bunyawanichakul, G. J. Walker, J. E. Sargison, and P. E. Doe, "Modelling and Simulation of Paddy Grain (Rice) Drying in a Simple Pneumatic Dryer," Biosyst. Eng., vol. 96, no. 3, pp. 335-344, Mar. 2007, DOI: 10.1016/J.BIOSYSTEMSENG.2006.11.004.

[3] M. S. H. Sarker, M. N. Ibrahim, N. Ab. Aziz, and P. Mohd. Salleh, "Energy and rice quality aspects during drying of freshly harvested paddy with industrial inclined bed dryer," Energy Convers. Manag., vol. 77, pp. 389-395, 2014, DOI: 10.1016/j.enconman.2013.09.038. M. S. Sodha, N. P. Singh, and R. Chandra, "Drying of paddy in a bed dryer," Drying Technology, vol. 6, no. 2. pp. 251-254, 1988, DOI: 10.1080/07373938808916374

[5] P. C. Corrêa, F. S. da Silva, C. Jaren, P. C. Afonso, and I. Arana, "Physical and mechanical properties in rice processing," J. Food Eng., vol. 79, no. 1, pp. 137-142, Mar. 2007, DOI: 10.1016/J.JFOODENG.2006.01.037.

[6] C. F. X. Ansys, "Manual, User. . Ansys 2019 R2, CFX19, 2019." Ansys-CFX Company, 2019.

[7] Y. Yuan, L. Tan, Z. Zhao, Y. Xu, Y. Zhao, and Y. Yuan, "Multi-Scale and Multi-Layer Structural Modeling and Simulation on Drying of Grain Packing Porous Media," Dry. Technol., vol. 34, Mar. 2016, DOI: 10.1080/07373937.2016.1141213.

[8] A. Cubillos Varela and O. Barrero Mendoza, "Diseño e implementación de una estrategia de control predictivo para el secado de arroz paddy," Rev. Fac. Ing. Univ. Antioquia, no. 56, pp. 78-86, Oct. 2010.

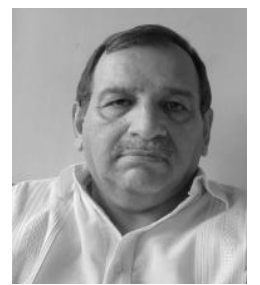

L.E. Vera-Duarte was born in Cúcuta, Norte de Santander, Colombia in 1957. He received the B.S. degree in mechanical engineering from Francisco de Paula Santander University in 1986, Specialization degree in environmental management engineering from Francisco de Paula Santander University in 1998, and the Mg degree in mechanical engineering from Nacional Experimental del Táchira University of Venezuela, in 2005. Since 1997, He has been an Associated Professor in the department of mechanical design, materials, processes, and thermals of the Universidad Francisco de Paula Santander.

$\mathrm{He}$ is director of the research group in Fluid and thermals (Fluter) classified C Minciencias. He is the author of a one book and more than 10 articles. His research interests include process energy efficiency.

$\mathrm{Mg}$ is a junior researcher classification of Minciencias

ORCID: https://orcid.org/0000-0001-8756-7779

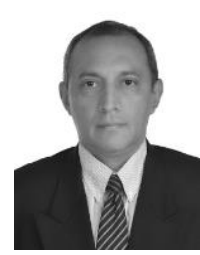

F. Moreno-Gamboa. He received the B.S. degree in mechanical engineering from Francisco de Paula Santander University in 1997. The Mg degree in mechanical engineering from Los Andes University of Bogota, in 2003 and $\mathrm{PhD}$ in engineering from Pontificia Bolivariana University of Medellin, in 2020. Since 2011, He has been an Associated Professor in the department of mechanical design, materials, processes, and thermals of the Francisco de Paula Santander University. He is a member of the research group in Fluid and thermals (Fluter) classified C Minciencias. He is the author of two books and more than five articles. His research interests include process energy efficiency, renewable energies y thermal engine. ORCID: https://orcid.org/0000-0002-3586-4306

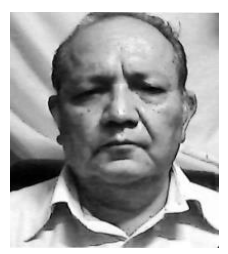

J.R. Eugenio-López was born in Pamplona, Norte de Santander, Colombia, in 1960. He received the B.S. degree in mechanical engineering from Francisco de Paula Santander University in 1984. Since 1994, he has been a professor in the department of mechanical design, materials, processes, and thermals of the Francisco de Paula Santander University.

He is the director of the Fluids and Thermal Research Seminar (Si-Fluter) at the Universidad Francisco de Paula Santander. His research interests include process energy efficiency. ORCID: https://orcid.org/0000-0001-8495-700X 